\title{
The Association between Preoperative Plasma C-Reactive Protein (CRP) Level and Postoperative Adult Heart Surgery Outcome
}

\author{
Bilehjani Eissa1, Fakhari Solmaz ${ }^{1,2}$, Farzin Haleh1, Mirinezhad Mousa', Shadvar Kamran1, \\ Yaghoubi Alireza ${ }^{3}$, Ranjbar Shirin ${ }^{4}$ \\ ${ }^{1}$ Department of Anesthesiology, Tabriz University of Medical Sciences, Tabriz, Iran \\ ${ }^{2}$ Shaid Gazi Hospital, Tabriz, Iran \\ ${ }^{3}$ Iran University of Medical Sciences, Tehran, Iran \\ ${ }^{4}$ Tabriz University of Medical Sciences, Tabriz, Iran \\ Email: 'solmaz_fakhari@yahoo.com
}

Received 9 August 2016; accepted 16 September 2016; published 19 September 2016

Copyright (C) 2016 by authors and Scientific Research Publishing Inc.

This work is licensed under the Creative Commons Attribution International License (CC BY). http://creativecommons.org/licenses/by/4.0/

(c) (i) Open Access

\section{Abstract}

Introduction: Careful history and physical examinations are the best ways for preoperative evaluation. Currently, we are recommended to rely on doing them rather than unnecessary and costly laboratory tests for confirmation or diagnosis of disease. The aim of study is the survey of CRP level association to decide further evaluation and expert consultation, newly diagnosed problems and possible effect on postoperative mortality and morbidity. Methods and Materials: In a descriptive retrospective study, hospital documentation of 620 patients older than 18 years undergone heart surgery in Tabriz Shahid Madani hospital was evaluated. Addition to plasma CRP level, patient's demographic information, type of surgery, preoperative significant tests, delay time in surgery start time after anesthesiology visit, cause of requested specialty consultation and treatment recommendation, postoperative complications and mortality rate were recorded and analyzed. Patients were classified according to preoperative plasma CRP level to five groups as negative, +1 , $+2,+3$ and not measured (i.e. they considered as normal $(0-5 \mathrm{mg} / \mathrm{l})$, mildly $(5-40 \mathrm{mg} / \mathrm{l})$, moderately (40 $-200 \mathrm{mg} / \mathrm{L}$ ) or severely increased ( $>200 \mathrm{mg} / \mathrm{l})$ groups). Results: 0 f 620 patients, 402 were male and 218 were female. There was not statistically significant correlation among demographic variables (gender, age, weight, and height), heart disease diagnosis and the type of surgery in five groups. In 79 individuals, they were done specialty consultations that most common of them were neurology consultation because of impaired renal laboratory tests. Only 2 cases were due to high CRP level. In any of cases, this preoperative consultation didn't result from new disease cases. CRP plasma level hadn't association with preoperative red blood cell sedimentation level. Prevalence of preoperative acute myocardium infarction was higher in *Corresponding author. 
patients with high CRP level. In group +1, delay time was lower than other groups. The most common causes were cardiac causes. There wasn't statistically significant correlation between CRP level and different postoperative complications. There wasn't significant association between ICU stay time and postoperative hospital stay time and plasma high CRP level. Conclusion: Probably, plasma CRP level increases before surgery in acute myocardial infarction and results in high mortality rate. It seems that routine measurement of CRP in candidates for heart operation is beneficial for mortality rate prediction, so its increasing level can't help to diagnosis newly cases and it isn't prudent to consult with specialist.

\section{Keywords}

C-Reactive Protein, Heart Surgery, Postoperative Complication, Postoperative Mortality

\section{Introduction}

For planning safe operation, anesthesiologist should accumulate adequate information, know patients' preoperative physiologic condition and optimize his or her clinical situation. Information resources are various and include history, physical examination, laboratory tests and others (e.g. x-ray, CT scan ...) [1]. The extend of using of any data resources depends on patients clinical condition, the type of surgery and anesthesiology and surgery team training level in prediction and prevention of complication and must use available, low risk and cheap but effective sources [1]-[3]. Although, the best ways of evaluation and obtaining information before surgery are exact history and physical examination [1] [4], some simple tests for clinical findings confirmation, severity of pathologic cases help to unknown problems [5]. In recent decades, results showed that unfortunately, unnecessary tests were done in candidates for surgery [3] [6] [7]. These tests not only help to undiagnosed diseases but result in costly programs, delay of surgery time, increase hospital stay and on the other hand, patients have been exposed intervention risks.

CRP is a plasma active reactant phase protein (normal: $0-5 \mathrm{mg} / \mathrm{L}$ ) that increases approximately in every type of inflammation and returns rapidly to normal level in recovery time [8]. In various studies, specificity and sensitivity of test had been evaluated in diagnosis and management of diseases. CRP test is routinely performed in patients that are undergone heart surgery in Shahid Madani hospital. Currently, the association between CRP and cardiovascular diseases (i.e. MI, stroke) was reported in patients with normal upper limit of CRP. The aim of study is evaluation of abnormal CRP level and its impact on further survey and specialty consultation, newly diagnosed problems, and finally its questionable role on mortality and morbidity.

\section{Methods and Materials}

This retrospective descriptive study was done on patients undergone heart surgery in Tabriz Shahid Madani Hospital, 2014. Inclusion criteria were age older than 18 years old, open heart surgery and registered and recorded data in hospital registry system. Individuals, who suffered from emergency operations or admission before surgery, urgent operations, postponing surgery plan for more than 7 days, or canceled surgery, were excluded from this study. Trained nurse who was familiar with patients' information, type of heart surgery and anesthetic technique and medical student recorded data on a prepared questionnaire. The data collection form prepared after a pilot study on 20 registries by the research group. Variables included patients' demographic and file data (e.g. hospital admission code number, gender, age, sex, weight and height), diagnosis of heart disease and cause of surgery (diagnosis before surgery), left ventricle ejection fraction, pulmonary artery pressure higher than 40 $\mathrm{mmHg}$, type of surgery, mellitus diabetes, smoking, comorbid diseases, history of myocardial infarction or angina, body temperature before operation, results of laboratory tests (e.g. hematocrit, white blood cell and platelet count, creatinine, blood nitrogen urea, fasting blood sugar, C-reactive protein, red blood cell sedimentation rate), consultation with other specialists and delay or cancellation of surgery due to it, newly diagnosed disease and gap time between anesthesia visit and operation.

Postoperative, they recorded variables such as required time for mechanical ventilation, ICU and hospital stay days, postoperative complications (e.g. hemodynamic instability, inotrope usage, and arrhythmia), respiratory 
(mechanical ventilation $>48$ hours, tracheostomy), renal (anuria, oliguria, $\mathrm{cr}>2 \mathrm{mg} / \mathrm{dl}$, need to dialysis), infectious (sepsis, mediastinitis), blooding/open sternum (need to reoperation for bleeding control), neurologic (cerebrovascular event, agitation, hallucination or psychosis), etc.(icter, epistaxis, hematuria, ...) and mortality rate. According to CRP test, the patients were initially classified into CRP measured or not measured groups. Then according to CRP value, they are grouped into normal $(0-5 \mathrm{mg} / \mathrm{l})$, mildly $(5-40 \mathrm{mg} / \mathrm{l})$, moderately $(40-200$ $\mathrm{mg} / \mathrm{L})$ or severely increased ( $>200 \mathrm{mg} / \mathrm{l})$. These collected data were analyzed using SPSS software version 16.0 (SPSS Inc., Chicago: IL). The data were presented using descriptive methods (frequency, percentage, mean \pm standard deviation). Parametric data were analyzed using independent sample t-test and non-parametric data using Pearson's chi-square or Mann-Whitney U test (Fisher's Exact Test if $\mathrm{n}<5$ ). P-values less than 0.05 were considered statistically significant. All P-values were 2-tailed.

\section{Results}

Overall, 642 patients' file were evaluated that 22 of them were excluded from study because the lack of inclusion criteria. 22 of them were excluded from study due to inclusion criteria and 620 patients' data were analyzed (Figure 1). In 3 cases, surgical plan postponed for more than 7 days, surgical plan canceled in 4 cases and changed to medical management, elective plan changed to urgent surgery in 7 cases and finally interventional methods used instead of surgery in 8 patients.

Of 620, 402 cases were male and 218 were female. In only 442 patients (71\%), the preoperative CRP was measured. Types of performed surgeries included coronary artery bypass grafting, ASD and VSD closure, valve replacement or repair, cardiac mass resection, Bental operation and pulmonary artery thromboembolectomy. Data analysis was performed in two stages. First, data were compared between CRP measured with not measured group. These two groups had same demographic data, smoking, diabetes mellitus, angina, recent MI, body temperature, LVEF, hematocrit, WBC and platelet counts, ESR, creatinine, type of the surgeries and postoperative morbidity and mortality ( 23 vs. 14 cases, respectively). In second phase, according to serum CRP level, it was normal, mildly increased, moderately increased or severely increased in $372(84.2 \%), 17(3.8 \%), 14(3.2 \%)$ and 39 cases $(8.8 \%)$, respectively. Table 1 shows demographic data and preoperative variables of various preoperative CRP level groups. Demographic data were not different in four CRP level groups. Except for preoperative smoking and recent MI other preoperative variables were same in four groups. Smoking habit and recent MI were more prevalent in severely increased CRP group.

Due to the type of surgery, the four CRP group had no significant differences. Preoperative ESR wasn't different between four CRP groups (Table 2) and ESR had no association with postoperative complications or in hospital mortality.

Except of cardiac, neurologic and miscellaneous (epistaxis, hematuria and GI bleeding) complications, all of other postoperative complications were high in severely increased CRP group. When comparing this group to other three groups, postoperative morbidity and mortality were $56.4 \%$ vs. $37.5 \%$ and $15.4 \%$ vs. $4.2 \%$, respectively. Comparing to some of other groups, need to ventilator support or ICU and hospital stay days were significantly higher in severely increased CRP group. Mortality rate also was high in severely increased CRP group (Table 3). Mortality rate increased with aging, presence of preoperative angina, $\mathrm{EF}<40 \%$ and consultation.

79 patients had been performed 105 consultations. Most of them were with neurology, infectious disease specialty, pulmonology, endocrinology and nephrology, respectively. The most common causes of them were due

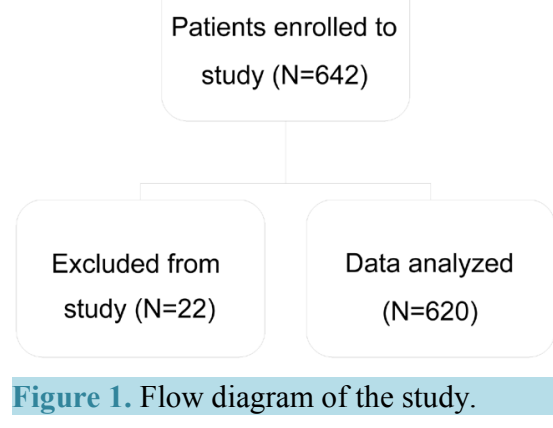


Table 1. Demographic and preoperative variables of various preoperative CRP level groups.

\begin{tabular}{cccccc}
\hline & \multicolumn{5}{c}{ CRP groups } \\
\cline { 2 - 5 } & $\begin{array}{c}\text { Normal } \\
(0-5 \mathrm{mg} / \mathrm{l}) \mathrm{N}=372\end{array}$ & $\begin{array}{c}\text { Mildly increased } \\
(5-40 \mathrm{mg} / \mathrm{l}) \mathrm{N}=17\end{array}$ & $\begin{array}{c}\text { Moderately increased } \\
(40-200 \mathrm{mg} / \mathrm{L}) \mathrm{N}=14\end{array}$ & $\begin{array}{c}\text { Severely increased } \\
(>200 \mathrm{mg} / \mathrm{l}) \mathrm{N}=39\end{array}$ & P-value \\
\hline Male/Female & $231 / 141$ & $13 / 4$ & $7 / 7$ & $22 / 17$ & $>0.05$ \\
Age (year) & $57.6 \pm 12.2$ & $61.9 \pm 9.4$ & $62.0 \pm 10.4$ & $58.3 \pm 17.3$ & $>0.05$ \\
Weight (kg) & $71.6 \pm 12.8$ & $74.5 \pm 13.1$ & $72.0 \pm 13.5$ & $68.2 \pm 12.7$ & $>0.05$ \\
Height (cm) & $164.6 \pm 8.3$ & $164.1 \pm 7.5$ & $163.8 \pm 8.6$ & $162.2 \pm 8.0$ & $>0.05$ \\
Diabetes mellitus & $65(17.5 \%)$ & $2(11.7 \%)$ & $2(14.3 \%)$ & $10(25.6 \%)$ & $>0.05$ \\
Smoking & $130(34.9 \%)$ & $6(35.3 \%)$ & $5(35.7 \%)$ & $26(66.7 \%)$ & $<0.05^{*}$ \\
Angina & $279(75 \%)$ & $13(76.5 \%)$ & $8(57.1 \%)$ & $28(71.8 \%)$ & $>0.05$ \\
Recent MI & $76(20.4 \%)$ & $3(17.6 \%)$ & $2(14.3 \%)$ & $15(38.5 \%)$ & $<0.05^{*}$ \\
LVEF & $41.2 \pm 8.53$ & $42.9 \pm 9.53$ & $45.3 \pm 6.64$ & $44.7 \pm 9.45$ & $>0.05$ \\
Temperature $(\mathrm{C})$ & $36.6 \pm 0.35$ & $36.6 \pm 0.32$ & $36.7 \pm 0.40$ & $36.7 \pm 0.33$ & $>0.05$ \\
Hematocrit $(\%)$ & $41.1(5.30)$ & $42.7(5.56)$ & $37.4(6.02)$ & $41.5(4.53)$ & $>0.05$ \\
WBC $\left(\times 1000 / \mathrm{mm}^{3}\right)$ & $7.7 \pm 2.66$ & $8.0 \pm 2.29$ & $8.6 \pm 3.26$ & $7.9 \pm 2.53$ & $>0.05$ \\
Platelet $\left(\times 1000 / \mathrm{mm}^{3}\right)$ & $219 \pm 68.3$ & $218 \pm 64.7$ & $206 \pm 52.3$ & $209 \pm 57.7$ & $>0.05$ \\
Creatinine $(\mathrm{mg} / \mathrm{dl})$ & $1.06 \pm 0.95$ & $1.03 \pm 0.32$ & $0.92 \pm 0.28$ & $1.14 \pm 1.11$ & $>0.05$ \\
\hline
\end{tabular}

*Significant differences between severely increased CRP group with other groups.

Table 2. Comparing preoperative erythrocyte sedimentation rate (ESR) in various preoperative CRP level groups.

\begin{tabular}{|c|c|c|c|c|c|}
\hline & & \multicolumn{4}{|c|}{ CRP groups } \\
\hline & & $\begin{array}{c}\text { Normal } \\
(0-5 \mathrm{mg} / \mathrm{l}) \mathrm{N}=372\end{array}$ & $\begin{array}{c}\text { Mildly increased } \\
(5-40 \mathrm{mg} / \mathrm{l}) \mathrm{N}=17\end{array}$ & $\begin{array}{l}\text { Moderately increased } \\
(40-200 \mathrm{mg} / \mathrm{L}) \mathrm{N}=14\end{array}$ & $\begin{array}{l}\text { Severely increased } \\
(>200 \mathrm{mg} / \mathrm{l}) \mathrm{N}=39\end{array}$ \\
\hline \multirow{5}{*}{ ESR } & Normal N (\%) & $235(63.2)$ & $11(64.7)$ & $10(71.4)$ & $32(82.1)$ \\
\hline & Moderately increased N (\%) & $70(118.8)$ & $4(23.5)$ & $3(21.4)$ & $4(10.2)$ \\
\hline & Severely increased N (\%) & $31(8.3)$ & $1(5.9)$ & $1(7.2)$ & $2(5.1)$ \\
\hline & Not measured N (\%) & $36(9.7)$ & $1(5.9)$ & $0(0)$ & $20(51.3)$ \\
\hline & total & 372 & 17 & 14 & 39 \\
\hline
\end{tabular}

to impaired renal tests, leukocytosis, high blood sugar level and history of CVA. Only in 2 cases, it was done because of High CRP level. In 20 cases, clinician recommended operation delay and further tests. Not at all, consultation result in newly diagnosed disease and complication rate $(51.9 \%$ vs. $35.3 \%$, P-value $=0.004)$ and mortality rate $(17.7 \%$ vs. $5.7 \%$, P-value $=0.001)$ were higher than others. CRP level hadn't correlation by gap time with anesthesiologist visit and operation.

\section{Discussion}

Careful history and physical examinations are best ways for preoperative evaluation. Currently, we are recommended to rely on doing them rather than unnecessary and costly laboratory tests for confirmation or diagnosis of disease. Although, data resources are various (e.g. history, physical examination, laboratory tests...) [1] [3], anesthesiologist must select the most effective source. Anesthesiologist should consider patient physiologic status, type of surgery and surgery and anesthesia team training in prediction, prevention and treatment of complications before test or specialty consultation. Before many of surgery procedures, addition to history and close 
Table 3. postoperative characteristics, complications and mortality rate of various preoperative CRP level groups.

\begin{tabular}{|c|c|c|c|c|c|}
\hline & \multicolumn{4}{|c|}{ CRP groups } & \multirow[b]{2}{*}{$\mathrm{P}$ value } \\
\hline & $\begin{array}{c}\text { Normal } \\
(0-5 \mathrm{mg} / \mathrm{l}) \mathrm{N}=372\end{array}$ & $\begin{array}{l}\text { Mildly increased } \\
(5-40 \mathrm{mg} / \mathrm{l}) \mathrm{N}=17\end{array}$ & $\begin{array}{c}\text { Moderately increased } \\
(40-200 \mathrm{mg} / \mathrm{L}) \mathrm{N}=14\end{array}$ & $\begin{array}{l}\text { Severely increased } \\
(>200 \mathrm{mg} / \mathrm{l}) \mathrm{N}=39\end{array}$ & \\
\hline Cardiac N (\%) & $128(34.4)$ & $8(47.1)$ & $6(42.9)$ & $18(46.2)$ & $>0.05$ \\
\hline Respiratory N (\%) & $35(9.4)$ & $2(11.8)$ & $1(7.1)$ & $8(20.5)$ & $<0.05^{*}$ \\
\hline Renal N (\%) & $17(4.5)$ & $1(5.9)$ & $2(14.3)$ & $5(12.8)$ & $<0.05^{*}$ \\
\hline Infectious N (\%) & $13(3.4)$ & $0(0)$ & $1(7.1)$ & $8(20.5)$ & $<0.05^{*}$ \\
\hline Bleeding or unclosed sternum $\mathrm{N}(\%)$ & $14(3.8)$ & $1(5.9)$ & $1(7.1)$ & $5(12.8)$ & $<0.05^{*}$ \\
\hline Neurologic N (\%) & $22(5.9)$ & $1(5.9)$ & $1(7.1)$ & $2(5.1)$ & $>0.05$ \\
\hline Miscellaneous N (\%) & $18(4.8)$ & $1(5.9)$ & $1(7.1)$ & $2(5.1)$ & $>0.05$ \\
\hline Complications (all types) & $137(36.8)$ & $9(52.9)$ & $5(35.7)$ & $22(56.4)$ & $<0.05^{*}$ \\
\hline Mortality N (\%) & $15(4 \%)$ & $1(5.9)$ & $1(7.1)$ & $6(15.4)$ & $<0.05^{*}$ \\
\hline Ventilator support (h) & $20.2 \pm 1.3$ & $20.6 \pm 5.5$ & $20.1 \pm 7.9$ & $24.3 \pm 5.9$ & $<0.05^{*}$ \\
\hline ICU stay (day) & $4.5 \pm 0.2$ & $4.2 \pm 0.7$ & $5.0 \pm 1.4$ & $5.7 \pm 3.5$ & $<0.05^{*}$ \\
\hline Hospital stay (day) & $8.4 \pm 0.3$ & $7.5 \pm 1.1$ & $6.6 \pm 0.8$ & $9.1 \pm 3.1$ & $<0.05^{*}$ \\
\hline
\end{tabular}

"Significant differences between severely increased CRP group with other groups. ESR wasn't different in various preoperative CRP level.

physical examination, some simple and cheap laboratory tests are performed [5] according to published guidelines. These unnecessary tests in patients' candidates for operation [3] [6] [7] couldn't help to new disease diagnosis and result in further costs, ineffective consultation, delay in operation, increased hospital stay time and probably have been exposed patients to risks of interventions. CRP is an acute phase protein and is very rare in plasma healthy subjects but in inflammation reactions increases suddenly [9] and intensity of elevation has direct association with severity of infection or inflammation [10]. So, it has predicted role that it's preoperative elevation as correlation with high morbidity and mortality rate.

Patients undergoing heart surgery under CPB frequently experience systemic reactions that causes postoperative morbidity and prolonged hospital stay [8]. Some studies demonstrated increased preoperative levels of CRP and adverse events [10]-[13]. In Agda Mezzomo et al. study, similar variables were analyzed and were shown risk of mortality and readmission to hospital for cardiovascular reasons that related to high preoperative levels of CRP [14]. Whether measurement of plasma CRP level in patients undergo heart surgery is required for optimization of preoperative condition or not? It is a controversy and we preformed this study for this reason. We understand when plasma CRP level is high; we should attempt to search its cause in same patient with heart disease and wouldn't follow specialty consultation. In other study, preoperative CRP $>3 \mathrm{mg} / \mathrm{dl}$ can predict incidence of postoperative complications such as respiratory dysfunctions [15]. Cappabianca et al. showed this event with CRP higher than $0.5 \mathrm{mg} / \mathrm{dl}$ [9]. In Pool et al. study, preoperative symptoms were associated with postoperative hospital stay [16]. For example, in acute myocardial infarction, CRP measurement is the best and most sensitive test that can obtain signs of necrosis or inflammation of myocardium [17] [18]. In coronary arteries stenosis, CRP is positive in cases with necrosis and negative in cases without necrosis. Our study proved this topic and showed that in group $+3 \mathrm{CRP}$, the prevalence of postoperative acute myocardial infarction was higher. Elevated CRP was more frequently found in patients who died [19]. It seems that in teaching hospital follow logic course regard to CRP elevation so, in very rare cases were performed consultation and in almost patients, we explained CRP elevation with heart disease presence and used it as prediction factor of postoperative mortality and complications rate. Choi et al. reported that preoperative CRP elevation was independent and potent for postoperative cardiovascular events [20]. Biancari et al. showed increasing of postoperative mortality and morbidity in patients with CRP higher than $1 \mathrm{mg} / \mathrm{dl}$ [21]. In our study, plasma CRP level elevation had associated with postoperative mortality but no with complication. Clearly, we couldn't confirm these results but our results were same as Gaudin et al. study that showed Preoperative CRP level cannot causes in-hospital 
postoperative complication [10]. Regard to mortality and morbidity rate, our study confirmed previous studies [9] [20] [21].

\section{Conclusion}

Although consultation could not be entailed to new disease diagnosis, mortality and complication rate were higher in these patients. Probably, this means high risk patients referred to specialist. It seems that preoperative high level CRP results in delay of surgery. Yet, CRP routine measurement in patients undergone heart surgery plays predictive role for in-hospital mortality and cannot help to new and unknown cases or optimization of preoperative situation.

\section{References}

[1] Ferrando Alvaldi, C., Buttigglirei, A., Pagano, E., Bonetto, C., Arione, R., et al. (2005) Guidelines for Preoperative Assessment: Impact on Clinical Practice and Costs. International Journal for Quality in Health Care, 17, 323-329. http://dx.doi.org/10.1093/intqhe/mzi039

[2] Bernard, N.A., Williams, R.W. and Spencer, E.M. (1994) Preoperative Patient Assessment: A Review of Literature and Recommendations. Annals of the Royal College of Surgeons of England, 76, 293-297.

[3] Bryson, G.L., Wyand, A. and Bragg, P.R. (2006) Preoperative Testing Is Inconsistent with Published Guidelines and Rarely Changes Management. Canadian Journal of Anesthesia, 53, 236-241. http://dx.doi.org/10.1007/BF03022208

[4] Van Klei, W.A., Grobbee, D.E., Rutten, C.L., Hennis, P.J., Knape, J.T., Kalkman, C.J., et al. (2003) Role of History and Physical Examination in Preoperative Evaluation. European Journal of Anaesthesiology, 20, 612-618. http://dx.doi.org/10.1097/00003643-200308000-00004

[5] Johnson, R.K. and Mortimer, A.J. (2002) Routine Preoperative Blood Testing: Is It a Necessary? Anaesthesia, 57, 914917. http://dx.doi.org/10.1046/j.1365-2044.2002.02750.x

[6] Mancuso, C.A. (1999) Impact of New Guideline on Physicians' Ordering of Preoperative Tests. Journal of General Internal Medicine, 14, 166-172. http://dx.doi.org/10.1046/j.1525-1497.1999.00308.x

[7] Krishnammurthy, A., Dutta, D., Phililps, J. and Methal, N. (2007) Are We Still Performing too Many Blood Tests? Quality and Safety in Health Care, 16, 400. http://dx.doi.org/10.1136/qshc.2007.023077

[8] Won Song, S., Yi, G.J., Lee, S., Nam Youn, Y., Young Sul, S. and Jong Yoo, K. (2008) Perioperative Indicators of Stress Response and Postoperative Inflammatory Complications in Patients Undergoing Off-Pump Coronary Artery Bypass Surgery.

[9] Cappabianca, G., Paparella, D., Visicchio, G., Capone, G., Lionetti, G., Numis, F., et al. (2006) Preoperative C-Reactive Protein Predicts Mid-Term Outcome after Cardiac Surgery. The Annals of Thoracic Surgery, 82, 2170-2178. http://dx.doi.org/10.1016/j.athoracsur.2006.06.039

[10] Gaudino, M., Nasso, G., Andreotti, F., Minniti, G., Lacoviello, L., Donati, M., et al. (2002) Preoperative C-Reactive Protein Level and Outcome Following Coronary Surgery. European Journal of Cardio-Thoracic Surgery, 22, 521-526. http://dx.doi.org/10.1016/S1010-7940(02)00436-0

[11] Mezzemo, A., Junior, O. and Portal, V. (2011) Preoperative C-Reactive Protein Predicts Respiratory Infection after Coronary Artery Bypass Graft Surgery. Arquivos Brasileiros de Cardiologia, 97, 365-371.

[12] Milazzo, D., Biasucci, L.M., Luciani, N., Matinelli, L., Canosa, C., Schiavello, R., et al. (1999) Elevated Levels of C-Reactive Protein before Coronary Artery Bypass Grafting Predict Recurrence of Ischemic Events. American Journal of Cardiology, 84, 459-461. http://dx.doi.org/10.1016/S0002-9149(99)00333-1

[13] Palmerini, T., Marzocchi, C., Reggiani, L.B., Savini, C., Marinelli, G., et al. (2007) Preoperative C-Reactive Protein Levels Predict 9-Month Mortality after Coronary Artery Bypass Grafting Surgery for the Treatment of Left Main Coronary Artery Stenosis. European Journal of Cardio-Thoracic Surgery, 31, 685-690. http://dx.doi.org/10.1016/j.ejcts.2006.12.029

[14] Boeken, U., Feindt, P., Zimmermann, N., Kalweit, G., Petzold, T. and Gams, E. (1998) Increased Preoperative C-Reactive Protein (CRP)-Values without Signs of an Infection and Complicated Course after Cardiopulmonary Bypass-Operations. European Journal of Cardio-Thoracic Surgery, 13, 541-545. http://dx.doi.org/10.1016/S1010-7940(98)00062-1

[15] Mirhosseini, S.J., Forouzannia, S.K., Ali-Hasan-Sayegh, S., Varaste Rezvan, H., Adollahi, M.H. and Mozayan, M.R. (2012) Preoperative C-Reactive Protein Can Predict Early Clinical Outcome Following Elective Off-Pump CABG Surgery in Patients with Severe Left Ventricle Dysfunction. Saudi Journal of Anaesthesia, 6, 327-331.

[16] Poole, L., Kidd, T., Leigh, E., Ronaldson, A., Jahangiri, M., Steptoe, A., et al. (2013) Depression, C-Reactive Protein 
and Length of Post-Operative Hospital Stay in Coronary Artery Bypass Graft Surgery Patients. Brain, Behavior, and Immunity, 37, 115-121.

[17] Miholic, J., Hudec, M., Muller, M.M., Domaing, E. and Wolner, E. (1986) Early Prediction of Deep Sternal Wound Infection after Heart Operation by Alpha-1 Acid Glycoprotein and C-Reactive Protein Measurements. The Annals of Thoracic Surgery, 42, 429-433.

[18] Barret, T.D., Hennan, J.K., Marks, R.M. and Lucchesi, B.R. (2002) C-Reactive Protein-Associated Increase in Myocardial Infarct Size after Ischemia-Reperfusion. Journal of Pharmacology and Experimental Therapeutics, 303, 10071013. http://dx.doi.org/10.1124/jpet.102.040600

[19] Lorezo, A., Pittella, F. and Rocha, A. (2012) Increased Preoperative C-Reactive Protein Levels Are Associated with in Hospital Death after Coronary Artery Bypass Surgery. Inflammation, 35, 1179-1183.

[20] Biancari, F., Lahtinen, J., Lepojarvi, S., Rainio, P., Salmela, E., Pokela, R., et al. (2010) Preoperative NT-proBNP and CRP Predict Perioperative Major Cardiovascular Events in Non-Cardiac Surgery. Heart, 96, 56-62. http://dx.doi.org/10.1136/hrt.2009.181388

[21] Ganem, F., Serrano, C.V., Fernandes, J.L., Blotta, M.H., Souuza, J.A., Nicolau, J.C., et al. (2003) Preoperative CReactive Protein and Outcome after Coronary Artery Bypass Surgery. The Annals of Thoracic Surgery, 76, $2007-2012$. http://dx.doi.org/10.1016/S0003-4975(03)01067-1

\section{Submit or recommend next manuscript to SCIRP and we will provide best service for you:}

Accepting pre-submission inquiries through Email, Facebook, LinkedIn, Twitter, etc. A wide selection of journals (inclusive of 9 subjects, more than 200 journals)

Providing 24-hour high-quality service

User-friendly online submission system

Fair and swift peer-review system

Efficient typesetting and proofreading procedure

Display of the result of downloads and visits, as well as the number of cited articles

Maximum dissemination of your research work

Submit your manuscript at: http://papersubmission.scirp.org/ 